\title{
Performance Assessment of Banana Drying using a Forced Convection Solar dryer
}

\author{
Aravind S, Milan K John, Rohinikumar B, Muraleedharan C
}

\begin{abstract}
Among all the noteworthy preservation techniques for food items, drying is considered to be one of the most consequential one. Different types of drying systems exist bottomed on the manner in which air flow takes place in the drying chamber and method of utilising incident solar radiation for drying. An indirect forced convection solar drying system with a dryer of varying cross section was considered in the present work. Banana (Musa Paradisiaca) was the raw material to be dried. Performance of the system at discharges of 0.03 and 0.02 $\mathrm{kg} / \mathrm{s}$, respectively for the specified mass of product was obtained and compared with open sun drying in the range of $66.3 \%-9.9 \%$ of wet basis moisture content. Drying process in chamber drying was completed four and two hours earlier than open sun drying at discharges of $0.03 \mathrm{~kg} / \mathrm{s}$ and $0.02 \mathrm{~kg} / \mathrm{s}$, respectively. Cumulative and tray wise instantaneous drying rates were found and obtained maximum drying rates of $75 \mathrm{~g} / \mathrm{h}$ and $15 \mathrm{~g} / \mathrm{h}$, respectively. Trend of moisture ratio against time was obtained by polynomial fitting which has satisfactory agreement with available mathematical model.
\end{abstract}

Keywords: Banana, Indirect solar drying, Tray wise drying, Experimental performance

\section{INTRODUCTION}

Solar drying is one of the most effective techniques for drying various food products. Majority of farmers are still inclined towards open sun drying (OSD) in India. It was found that the products with excess moisture content degrade in quality due to OSD [1]. Though conduction dryers are used, it is less common compared to convection dryers. The latter makes use of hot air to interact with products to be dried. Therefore, understanding the psychrometric properties of air is an essential prerequisite [2]. The drying performance of products not only depends on the air properties but the nature of the product also. The moisture content of products is commonly expressed in two ways namely wet basis and dry basis. Drying process deals with complex synchronous heat and mass transfer mechanisms and it is generally, an energy intensive technique. Till date, various types of solar dryers have been fabricated across the world. Depending upon the approach adopted for air movement, dryers are distinguished as natural and forced convection solar dryers whereas the same is distinguished as direct, indirect and mixed type dryers based on the nature of interaction of products with the incident radiation. The sole disparity between solar and open sun drying is mainly due to the exceptional features to improve the effect of irradiation. Some products undergo

Revised Manuscript Received on July 05, 2020.

*Correspondence Author

B Rohinikumar, Department of Mechanical Engineering, National Institute of Technology, Calicut, India. E-mail: rohinikumar@nitc.ac.in colour change and reduction in nutritional values due to direct solar exposure. This is where solar dryers come handy with their constructional advantages to avoid the same [3]. In such cases, indirect solar dryers can be used where products are dried using heated air as a result of greenhouse effect. The mass transfer mechanism involved in drying is not single fold. During the commencing stage of drying, presence of surface moisture is high and the mechanism involved can be either diffusion or convective mass transfer. But as drying continues, surface moisture level comes down and mass transfer becomes quite difficult. Bound moisture present in the products has to be brought to the surface which may take place by capillary action and then to drying air [4]. When vapour pressure of product moisture equalizes with that of ambient air vapour pressure, the moisture content is termed as equilibrium moisture content and no further moisture content change takes place unless the product is subjected to different surrounding conditions. Banana is a very commonly utilized fruit in human diet. But if they are not consumed on time, spoilage can occur very easily. This is because majority (roughly 70\%) of the mass of banana comprises of moisture content [5]. Hence, drying of bananas are required for extended shelf life. Hassnain et al. [6] carried out an experimental study to find out the drying performance of bananas (Musa acuminate) under different temperature ranges. Nguyen et al. [7] studied the impact of slice thickness required and arrived at an optimum thickness value. Manjarres et al. [8] studied the influence of air velocity on drying performance and compared the results. To the best possible knowledge from the authors, it was perceived in such a way that, drying performance study on varying cross section solar dryers is limited to a few. It is clear from the literature that the thermal performance of top trays is slightly low compared to bottom ones [9] for constant cross section solar drying chambers. So if the constant cross section dryers are replaced by converging type dryers, there will be an increment in air velocity from bottom to top trays which improves the heat transfer coefficient as air moves from bottom to top. This way, a better drying rate is expected out of top trays. The central scheme of the current work is to conduct the experimental studies on an indirect forced convection solar drying system which consists of a dryer of varying cross section with banana (Musa Paradisiaca) as the product. Performance of the system is studied using two disparate air discharges and outcomes are compared with the performance observed when the products were dried open in sun process by virtue of different drying characteristics.

Published by:

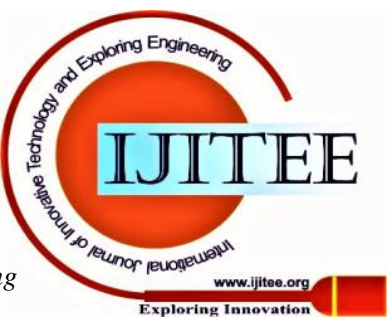




\section{Performance Assessment of Banana Drying using a Forced Convection Solar dryer}

Cumulative and tray-wise variation of moisture content with time is analysed and correlations are formulated for chamber drying process

\section{SOLAR DRYING SYSTEM}

\section{A. Working of Solar Drying System}

Fig. 1 depicts the representational figure and Fig. 2 reveals the photograph of the system under study in the present work. It consists of three main components: air blower, solar air heater and drying chamber. Air blower takes air from the atmosphere and increases the kinetic energy of the same which leads to forced flow of air to the air heater. Solar air heater is equipped with absorber plate which is painted with a selective coating that increases the absorptivity of the plate material. Air heater is insulated mainly on the lateral and lowermost portions in all possible mechanisms and it is equipped with a high transmissivity glass cover at the top. Glass cover allows majority of incident radiation to seep through it while blocking its return and thus providing the greenhouse effect. The purpose of air heater is to heat the incoming air from blower and direct it to the product chamber. The air heated by collector enters from the bottom, flows upwards and leaves from top of the drying chamber.

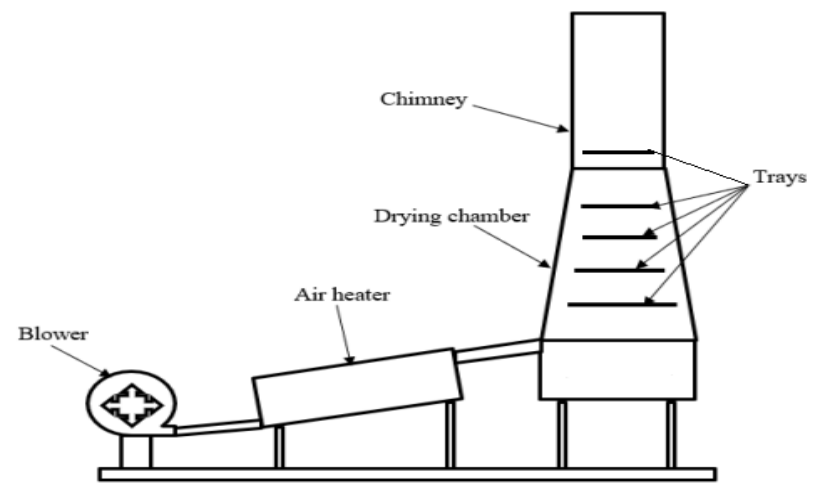

Fig. 1. Illustrative figure of solar drying system

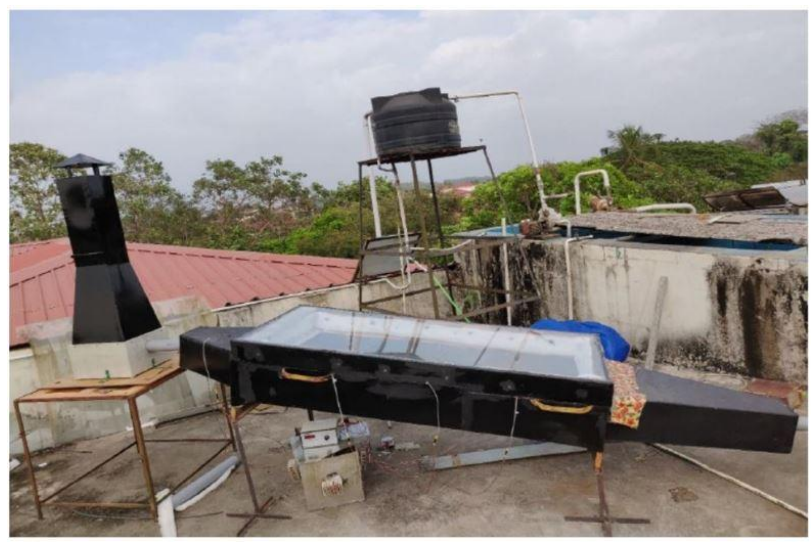

Fig. 2. Photograph of solar drying system

The trays present in the dryer is where the products are kept. All trays are positioned one over the other in the chamber. Hot air coming from air heater will be directed into the chamber and thus the products to be dried interact with the air by combined heat and mass transfer processes. Products lose moisture by this interaction and hence dried. The drying chamber used in the present work is of varying (decreasing) cross section in the direction of stream. Varying cross section could help the chamber to maintain possible uniformity in the tray wise drying along the path of the air flow by compensating the reduction in temperature difference [9] with increase in surface conductance.

\section{B. Experimentation}

In the present study, a $0.5 \mathrm{hp}$ air blower is chosen. Flat aluminium absorber plate is used in air collector. A single layer of glass sheet of $4 \mathrm{~mm}$ thickness is used as cover. The sides and bottom are insulated with PUF (Poly Urethane Foam) and wood, respectively. The air heater is inclined at an angle of $11.25^{\circ}$, same as the latitude of Calicut, Kerala. The fabrication of the heater was done as per ASHRAE guidelines[10]. Specifications of the heater and instruments used for conducting the experiments are provided in Table I. Drying chamber consists of five wire mesh trays of decreasing cross sectional area from bottom to top. Bottom tray can accommodate more mass of the product to be dried compared to top one. The exit of dryer is a chimney to ensure continuous air flow around the product, thus increasing the rate of drying compared to other designs.

Table I: Instrumentaion used for experimentation and spefications of solar Air heater

\begin{tabular}{|l|c|c|}
\hline \multicolumn{3}{|c|}{ Instrumentation } \\
\hline \multicolumn{1}{|c|}{ Instrument } & Range & Accuracy \\
\hline Pyranometer & $0-2000 \mathrm{~W} / \mathrm{m}^{2}$ & $\pm 10 \mathrm{~W} / \mathrm{m}^{2}$ \\
\hline $\begin{array}{l}\text { T-type } \\
\text { thermocouples }\end{array}$ & $-270^{\circ} \mathrm{C}$ to $370^{\circ} \mathrm{C}$ & $\pm 1^{\circ} \mathrm{C}$ \\
\hline $\begin{array}{l}\text { Digital weighing } \\
\text { balance }\end{array}$ & 0 to $5 \mathrm{~kg}$ & $\pm 1 \mathrm{~g}$ \\
\hline Anemometer & $0-20 \mathrm{~m} / \mathrm{s}$ & $0.1 \mathrm{~m} / \mathrm{s}$ \\
\hline \multicolumn{2}{|c|}{ Solar Air Heater Specifications } \\
\hline Dimensions & $1.8 \mathrm{~m} \times 0.8 \mathrm{~m} \times 0.8 \mathrm{~mm}$ \\
\hline Material & Aluminium \\
\hline Type Flat plate \\
\hline Air flow configuration & Under pass (single) \\
\hline
\end{tabular}

Bananas (Musa Paradisiaca) were chosen as product to be dried. The product was cut into thin slices of approximately 3 to $5 \mathrm{~mm}$ thickness [11]. Experiments were conducted initially with an air discharge $0.03 \mathrm{~kg} / \mathrm{s}$. The mass of product loaded was same in chamber and open sun. Mass of the product loaded in both modes was $500 \mathrm{~g}$. Product mass was distributed in solar drying mode according to the position of the tray as shown in Table II.

Table II: Tray wise distribution of mass

\begin{tabular}{|l|l|l|l|l|l|}
\hline Tray position & Top & II $^{\text {nd }}$ & III $^{\text {rd }}$ & IV $^{\text {th }}$ & $\mathrm{V}^{\text {th }}$ \\
\hline Mass $(\mathrm{g})$ & 55 & 55 & 86 & 146 & 158 \\
\hline
\end{tabular}

$100 \mathrm{~g}$ of sample was loaded in the hot air oven and the sample was heated in electric oven at a temperature of $105^{\circ} \mathrm{C}$ for 24 hours. The moisture content of sample at initial point of time was calculated using [8].

Published by:

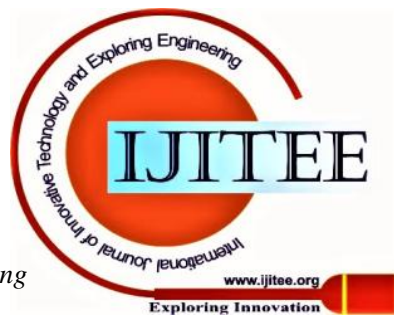




$$
I M C_{=} \frac{W_{i}-W_{f}}{W_{i}}
$$

The first set of experiments was conducted initially with an air discharge of $0.03 \mathrm{~kg} / \mathrm{s}$ and the second set of experiments, with $0.02 \mathrm{~kg} / \mathrm{s}$. The initial and final sample mass, maximum collector exit stream temperature, peak solar radiation, surrounding temperature range and time required to complete the drying process for the above mentioned air discharges are shown in Table III.

Table III: Comparison of thermal conditions and product mass at different flow rates

\begin{tabular}{|l|c|c|}
\hline $\begin{array}{l}\text { Mass flow rate } \\
(\mathrm{kg} / \mathrm{s})\end{array}$ & 0.03 & 0.02 \\
\hline Initial mass $(\mathrm{g})$ & 500 & 500 \\
\hline Final mass $(\mathrm{g})$ & 167 & 160.5 \\
\hline $\begin{array}{l}\text { Maximum collector exit } \\
\text { temperature }\left({ }^{\circ} \mathrm{C}\right)\end{array}$ & 51 & 57 \\
\hline $\begin{array}{l}\text { Peak global solar radiation } \\
\left(\mathrm{W} / \mathrm{m}^{2}\right)\end{array}$ & 850 & 880 \\
\hline $\begin{array}{l}\text { Ambient temperature range } \\
\left({ }^{\circ} \mathrm{C}\right)\end{array}$ & $25-35$ & $24-36$ \\
\hline $\begin{array}{l}\text { Time taken for chamber } \\
\text { drying (hours) }\end{array}$ & 9 & 11 \\
\hline
\end{tabular}

\section{RESULTS AND DISCUSSIONS}

The performance of system is evaluated upon carrying out experiments for different air discharges. The plot depicting the climatic data of the day of experiment along with exit stream temperature of the collector was as shown in Fig. 3 corresponding to discharge of $0.03 \mathrm{~kg} / \mathrm{s}$. Exit temperature variation with time is simulated under steady state conditions and compared with the trend obtained from experiments (refer Fig. 3). Since the rate of energy accumulated in the heater is not accounted in the steady state simulation, predicted results are obviously higher than the experimental observations throughout the day.

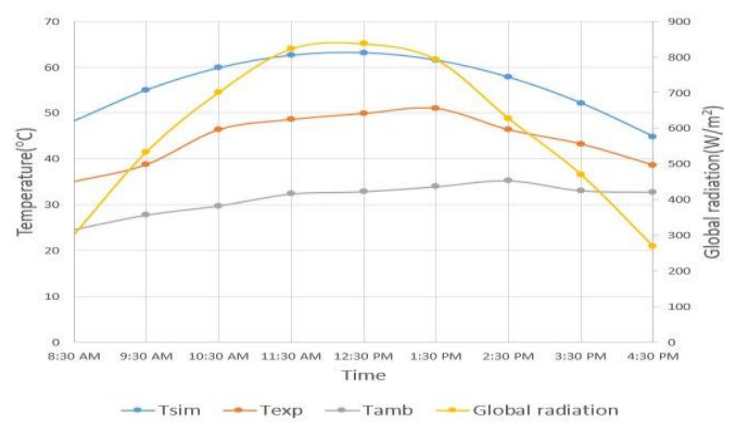

Fig. 3 Climatic data and temperature of air at the exit of the collector

\section{A. Drying Characteristics (For $0.03 \mathrm{~kg} / \mathrm{s}$ )}

A comparison study on wet basis moisture content between dryer and open sun is depicted in Fig. 4. The comparison was done between the two modes of drying from $66.3 \%$ to $9.9 \%$. Drying process in the chamber was completed four hours earlier than the OSD for the specified range. This is because the drying rates between the two modes of drying with time is different. Variation of drying rate with time in solar drying was compared with OSD as shown in Fig. 5.

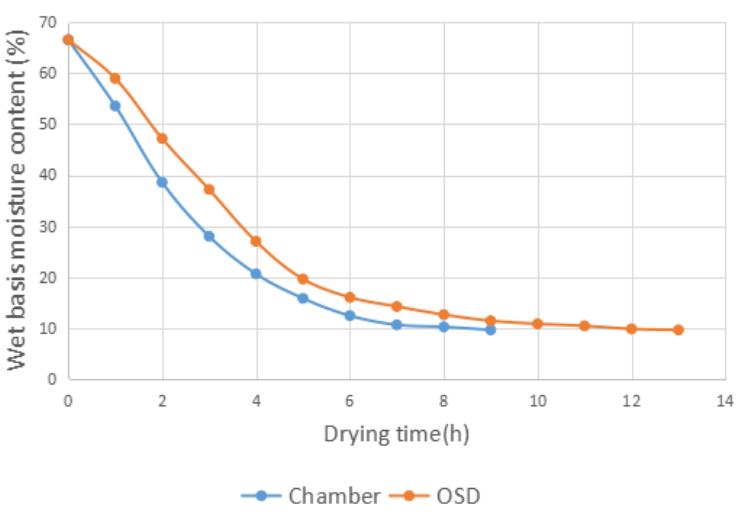

Fig. 4. Wet basis moisture comparison study between dryer and OSD

Utilisation of incident solar radiation for drying the sample in chamber drying process was different from OSD. Chamber drying process was accompanied by greenhouse effect which can be seen in almost all the solar collection devices. This is the reason for higher temperature and lower relative humidity for the air at the exit of the collector in chamber drying which causes higher moisture holding capacity for the air and consequent faster drying. Higher moisture holding capacity for the air leads to greater vapour pressure difference between the product-air interface and air stream which could be the reason for higher maximum drying rate in chamber drying compared to OSD. In addition to the vapour pressure difference, product exposed area \& air velocity also contributes to the rate of drying. Surface area of the product is more or less same in both modes of drying, but velocity of the air differs in both modes of drying. Therefore higher air velocity in chamber drying also contributes to the higher drying rates along with the vapour pressure difference.

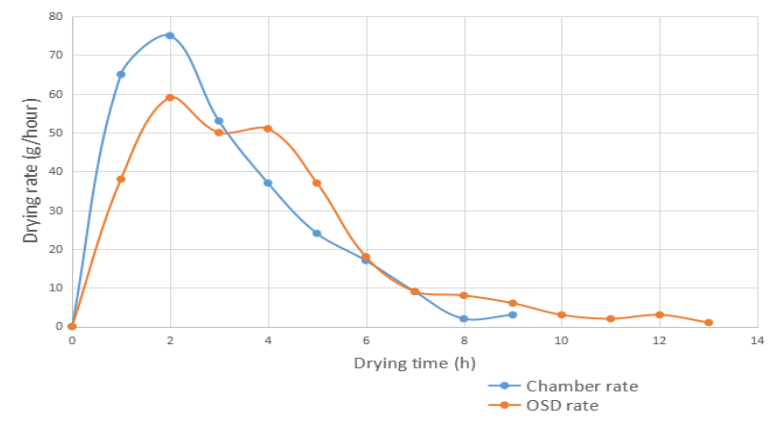

Fig. 5. Drying rate comparison between dryer and OSD

Trends of the variation of moisture content on wet basis were similar in both modes of drying. Variation of concentration gradient between the sample and the hot air with time might be the major reason for the trends of wet basis moisture content with time for both modes of drying. This can be justified with presence of surface and bound moistures in the product to be dried. Presence of surface moisture enhances the drying rates initially due to the nature of interaction with air in this period. Once the surface moisture is lost, product will be dried because of the presence of bound moisture. Interaction of bound moisture with air is unlike the interaction with surface moisture and drying rates while loss in bound moisture is relatively low.

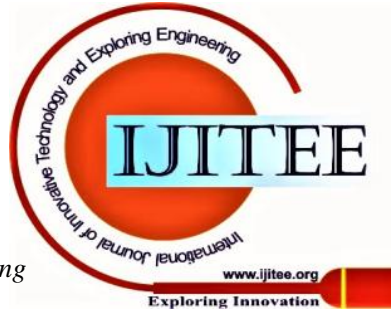




\section{Performance Assessment of Banana Drying using a Forced Convection Solar dryer}

Apart from the time required to cause the specified change in wet basis moisture content and drying rate, dried samples with reference to different modes of drying were different in other aspects like appearance. The fresh and dried samples with reference to two different modes of drying processes were compared as shown in Fig. 6. The chamber dried product was crispier and light in colour tone compared to fluffier and dark in colour from OSD. Drying characteristics are qualitatively similar at selected air discharges.

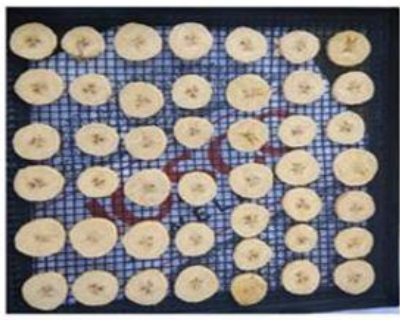

Chamber sample (before)

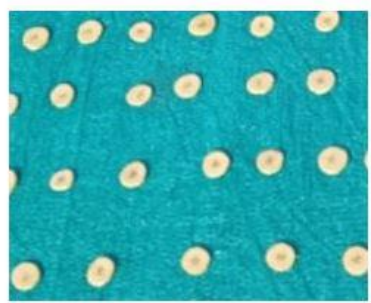

OSD sample (before)

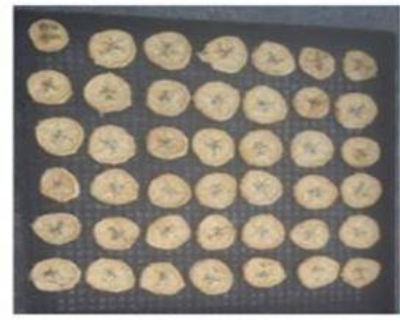

(after drying)

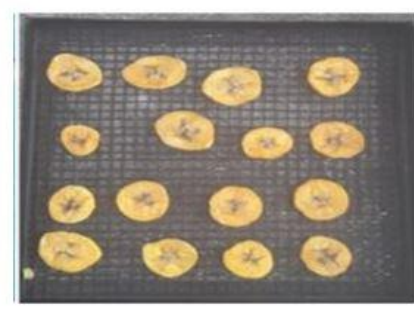

(after drying)
Fig. 6 Sample quality comparison between dryer and OSD

\section{B. Tray Wise Drying Rate Comparison}

Tray wise distribution of mass of the product to be dried was shown in Table II. Tray wise variation of drying rate with time was shown in Fig. 7. Top refers to the top most tray and fifth tray refers to the bottom most one.

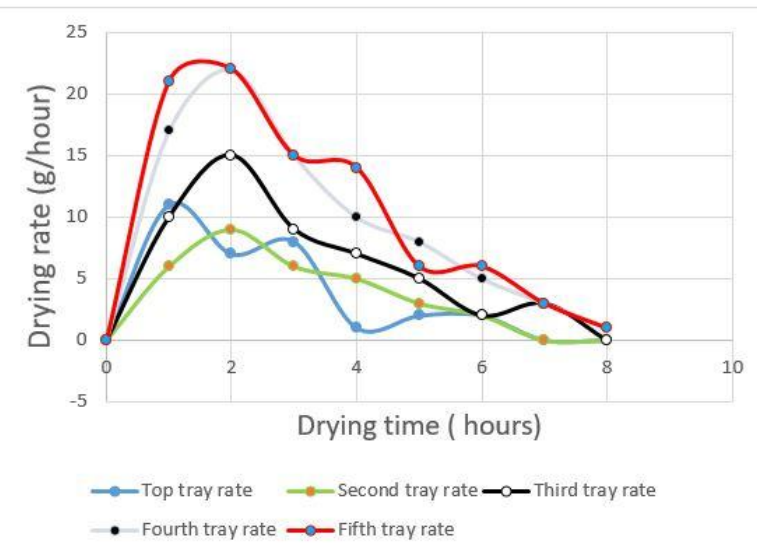

Fig. 7 Tray wise drying rate variation for $0.03 \mathrm{~kg} / \mathrm{s}$.

Considering the product mass in each tray, the top and second trays showed a maximum drying rate of $11 \mathrm{~g} / \mathrm{h}$ and $9 \mathrm{~g} / \mathrm{h}$, respectively which is satisfactory by virtue of the amount loaded in them. Highest drying rate was $22 \mathrm{~g} / \mathrm{h}$ for the bottom tray over which the mass of the product loaded was maximum. This rate can be attributed to the accelerated air flow through the upper trays due to its converging design. This is due to the improved convective heat and mass transfer coefficients between air and products in the top trays that results in improved heat and mass transfer rate between them. Highest fluctuation of drying rate at any instant between trays was $15 \mathrm{~g} / \mathrm{h}$ which is acceptable considering the variation in mass distribution.

\section{Performance Comparison}

The comparative study between dryer, open sun is carried out and the results for the selected air discharges are shown in Fig. 8. It was found that performance with reference to high discharge $(\mathrm{v}=8 \mathrm{~m} / \mathrm{s})$ showed better drying rate and less drying time compared to low discharge $(\mathrm{v}=5.34 \mathrm{~m} / \mathrm{s})$. From Table III, it is evident that the exit stream temperature of heater is more in the case of lower discharge which contributes to the higher temperature difference that leads to higher heat transfer rate and consequent higher drying rate. Higher velocity of air at higher mass flow rate leads to faster replacement of air for the interaction with the product to be dried in the chamber. This enhances the coefficient of convective heat and mass transfer at higher mass flow rates. Therefore, increase in heat and mass transfer rates due to higher velocity dominates the decrease of the same due to lower temperature difference at higher mass flow rates compared to the lower ones. This might be the reason for higher drying rates and lower duration required to complete the predetermined range of wet basis moisture content at higher discharges.

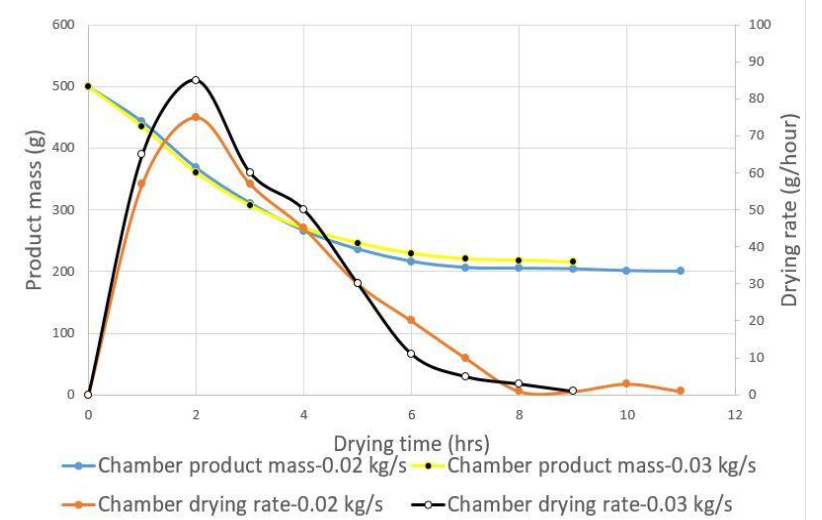

.Fig.8 Dryer performance comparison for selected air discharges

\section{Drying Kinetics Correlations And Literature Validation}

The moisture ratio (MR) of product at an instant during the drying process was obtained from the relation [12]:

$$
M R=\frac{M_{t}-M_{e}}{M_{i}-M_{e}} \cong \frac{M_{t}}{M_{i}}
$$

where $M_{i}$ is the initial, $M_{e}$ refers to the equilibrium and $M_{t}$ the instantaneous moisture content. The latter changes amidst drying. Moreover, $M_{e}$ is strongly dependent on chamber conditions. Variation of moisture ratio was found from the experimental observations and the same was plotted against time and depicted in Fig. 9 at an air discharge of $0.03 \mathrm{~kg} / \mathrm{s}$. The trend of the moisture ratio against time was qualitatively similar at lower discharges. To formulate drying model in terms of moisture ratio against time, the experimental data of moisture ratio was fitted using polynomial fitting at both the discharges.

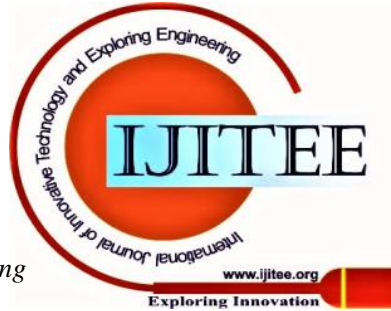




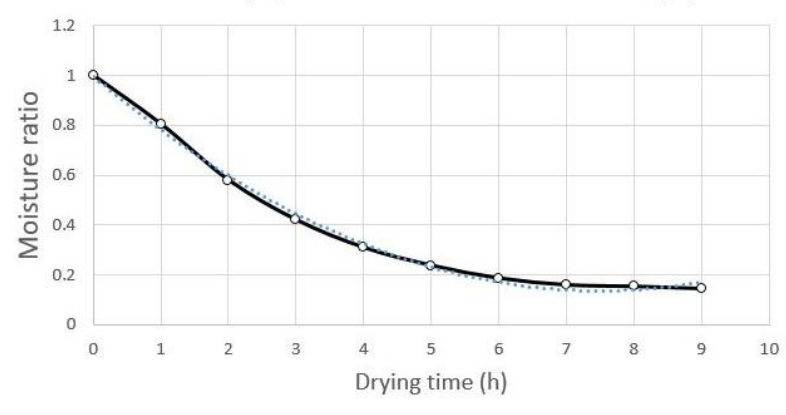

$\longrightarrow$ Moisture ratio (Exp) …..... Poly. (Moisture ratio (Exp))

Fig. 9. Moisture ratio trend with time $(0.03 \mathrm{~kg} / \mathrm{s})$

A second order polynomial of the following form is used:

$$
M R=1+K_{1} t+K_{2} t^{2}
$$

Table IV specifies the values of coefficients and correlation parameters of the polynomial fitting at both mass flow rates.

Table IV: Constants and correlation parameters

\begin{tabular}{|c|c|c|c|}
\hline $\begin{array}{c}\text { Mass flow } \\
\text { rate }(\mathrm{kg} / \mathrm{s})\end{array}$ & $\mathrm{K}_{1}$ & $\mathrm{~K}_{2}$ & $\mathrm{R}^{2}$ \\
\hline 0.03 & -0.2303 & 0.01536 & 0.996 \\
\hline 0.02 & -0.2105 & 0.01225 & 0.9917 \\
\hline
\end{tabular}

The developed drying correlation was compared with the mathematical model for the moisture ratio variation with time existing in literature [12] and reasonably good matching was found as depicted in Fig. 10.

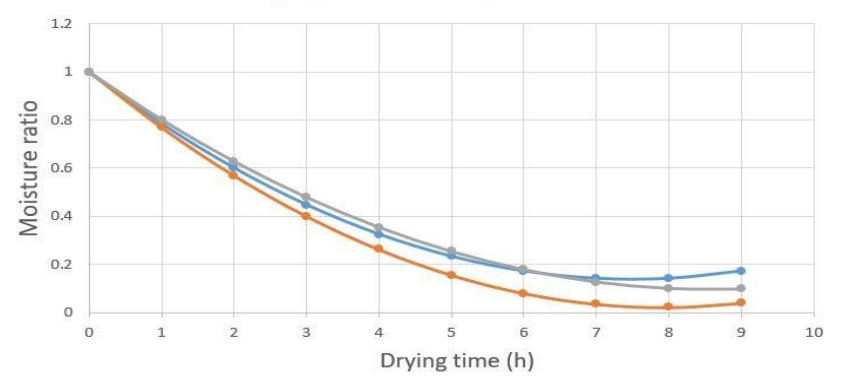

$\rightarrow$ Curve fitted-0.03 kg/s $\rightarrow$ Abhay et al.(2016)

$\rightarrow$ Curve fitted-0.02 kg/s

Fig. 10. Drying model comparison

\section{CONCLUSION}

The following are the outcomes of the current work:

$>$ Drying process was considered for the moisture content range of $66.3 \%$ to $9.9 \%$ on wet basis in chamber and OSD.

$>$ Drying process was completed in $9 \mathrm{~h}$ in chamber drying for a discharge of $0.03 \mathrm{~kg} / \mathrm{s}$.

$>$ Drying process at a discharge of $0.03 \mathrm{~kg} / \mathrm{s}$ was completed two hours earlier than with $0.02 \mathrm{~kg} / \mathrm{s}$.

$>$ Drying process in chamber drying was completed four and two hours earlier than open sun drying at air discharges of $0.03 \mathrm{~kg} / \mathrm{s}$ and $0.02 \mathrm{~kg} / \mathrm{s}$, respectively.

$>$ The maximum instantaneous drying rate was found out to be $75 \mathrm{~g} / \mathrm{h}$ at $0.03 \mathrm{~kg} / \mathrm{s}$.

$>$ The maximum instantaneous tray wise drying rate variation was found to be $15 \mathrm{~g} / \mathrm{h}$ at a discharge of 0.03 $\mathrm{kg} / \mathrm{s}$.
$>$ The chamber dried product was crispier and light in colour tone compared to fluffier and dark in colour from OSD.

$>$ Second degree polynomial was used to fit the trend of moisture ratio against time and found in good agreement with the existing mathematical model.

The future work proposed is conducting experiments with more sets of air flow rates with the same product for finding out the working condition that results in an optimum performance for collector as well as dryer. A simultaneous comparison study is also possible between flat plate and dimple shaped solar air heater.

\section{REFERENCES}

1. Sharma VK, Sharma TS, Garg HP (1991) Mathematical modeling and experimental evaluation of a natural convection type solar cabinet dryer. Energy Convers Manag 31(1):65-73

2. 2.Vega-Mercado H , Go'ngora-Nieto MM , Barbosa-Ca' novas GV (2001) Advances in dehydration of foods. J Food Eng 49(4):271-289

3. Karathanos VT (1999) Determination of water content of dried fruits by drying kinetics. J Food Eng 39:337-344

4. Babalis S (2006) Theoretical and experimental investigation of the heat and mass transfer phenomena during the drying of foods in hot air stream. PhD thesis, (In Greek) University of Thessaloniki

5. Prakash O, Kumar A (2013) Historical review and recent trends in solar drying systems. Int J Green Energy 10:690-738

6. 6.Hassnain AA (2009) Simple solar drying system for banana fruit. World J Agric Sci 5(4):446-455

7. Nguyen M-H, William Price E (2007) Air-drying of banana: Influence of experimental parameters, slab thickness, banana maturity and harvesting season. J Food Eng 79(1):200-207

8. Manjarres-Pinzon K, Cortes Rodriguez M, Rodriguez Sandaval E (2013) Effect of drying conditions on the physical properties of impregnated orange peel. Braz J ChemEng 30(3):667-676

9. El-Sebaii, A. A., Aboul-Enein, S., Ramadan, M. R. I., \& El-Gohary, H. G. (2002). Experimental investigation of an indirect type natural convection solar dryer. Energy Conversion and Management, 43(16), 2251-2266.

10. S.A., Yellott, J.I., and Wood, B. Application of ASHRAE standard 93-77 to the thermal performance testing of air solar collectors.

11. Terres H, Chavez S, Lizardi A, Morales JR. Study of the Banana Drying Process Using a Solar Dryer. 2017:1-6.

12. Abhay Lingayat, Chandramohan V.P., V.R.K. Raju. Design, Development and Performance of Indirect Type Solar Dryer for Banana Drying. Energy Procedia 109 ( 2017 ) 409 - 416.

\section{AUTHORS PROFILE}

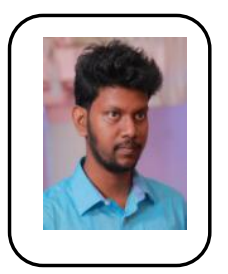

Aravind S is pursuing Master of Technology in Energy Engineering and Management in the Department of Mechanical Engineering from National Institute of Technology, Calicut. He is currently doing research work in combined solar dryer-desalination systems as part of his M.Tech project. His area of interest includes Solar thermal, cost effective renewable energy driven systems and Refrigeration \& Air conditioning systems.

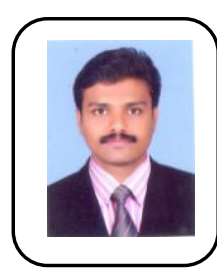

Milan K John is pursuing Ph.D in Mechanica Engineering from National Institute of Technology, Calicut. He is currently doing research work in the development of novel and cost effective solar drying system.

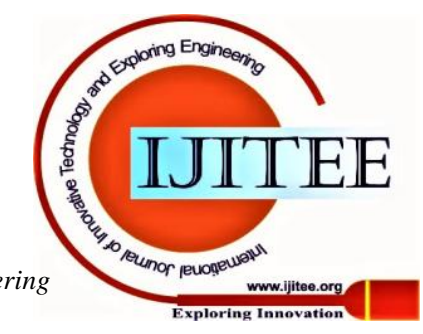


Performance Assessment of Banana Drying using a Forced Convection Solar dryer

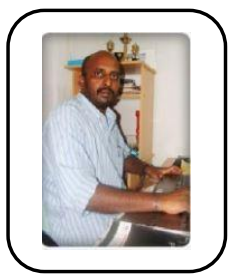

Dr. Rohinikumar B obtained his PhD Degree in Mechanical Engineering from National Institute of Technology, Calicut (2018). He completed his Master's Degree in Thermal Power Equipment from REC, Trichy (2002). He is currently working as an assistant professor in Department of Mechanical Engineering, National Institute of Technology; Calicut His research interests include Fluid Flow and Heat Transfer, Modeling and Simulation of Solar Energy Systems, Experimental investigations on Solar Energy Systems and Refrigeration \& Air-Conditioning

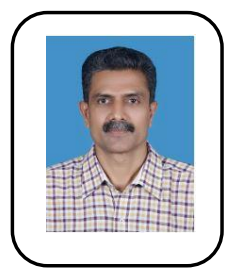

Dr. Muraleedharan C obtained his $\mathrm{PhD}$ Degree in Mechanical Engineering from University of Calicut, 2002. He completed his Master's Degree in Refrigeration \& Air conditioning, University of Calicut, 1983. He is currently working as professor (HAG) in Department of Mechanical Engineering, National Institute of Technology; Calicut. His research interests include Heat Pipes, Refrigeration \& Air Conditioning, Renewable Energy, Energy Conservation Fuels \& Combustion.

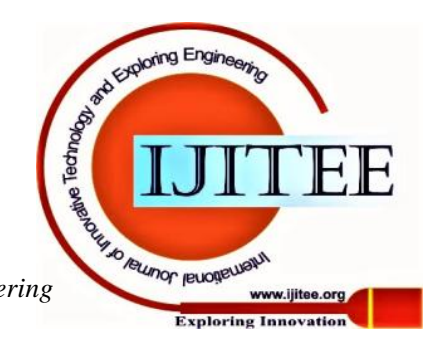

